\title{
DOYNE LECTURE INFLUENCES ON THE DEVELOPMENT OF CORNEAL TRANSPLANTATION
}

\author{
DOUGLAS J. COSTER \\ Adelaide. Australia
}

\begin{abstract}
My aim is to discuss several influences on the development of corneal transplantation. In particular, I wish to emphasise the impact of research on current practice, not just in the general sense but at the level of the individual surgeon-patient encounter. However, science is not the only influence on clinical practice. As in all spheres of human activity, current practice is influenced by the historical path as well as contemporary capability. My second aim is to emphasise the impact of historical and cultural influences on clinical practice and related science.
\end{abstract}

\section{SOME SIGNIFICANT HISTORICAL EVENTS}

Ophthalmologists in general are aware of the convoluted path along which the history of ideas on light and vision has evolved. However, the early contribution of an Oxford man, Robert Grosseteste, is often overlooked.

Grosseteste, a Franciscan monk. lived and worked in Oxford between 1229 and 1235 . He was sent to Oxford to teach in a new school set up by the Franciscans. While there he wrote a number of books. One rather slim volume, De Luce, has come to be accepted as one of the most important books in the history of science. In it, Grosseteste described how light filled the world, behaved in a mathematically predictable way, and entered the eye to provide the basis of visual perception. These views were not only a radical departure from the accepted ideas of the time. ideas which had been passed down from Greek and pre-Christian teachings, but they preceded the development of modern scientific ideas which underpinned the scientific revolution of the seventeenth century. Prior to Grossteste it was generally believed that the eyes emitted light rather than received it.

While Grosseteste was in Oxford he also achieved many things in an organisational sense. He achieved a level of cooperation between schools and was the first recorded Chancellor of the University. The origins of

Correspondence to: Professor D.J. Coster. FRACO, Department of Ophthalmology, Flinders Medical Centre, Bedford Park 5042, Adelaide, South Australia.
Oxford University are uncertain and contentious. There is no doubt, however, that Grosseteste was a very significant figure while at Oxford and after he left the city to become Bishop of Lincoln, the largest diocese in England, he would have been the one responsible for acquiring the papal assent required for the establishment of the University. It would seem that the origins of modern visual science and ophthalmology and the establishment of Oxford University were very closely linked through Grosseteste. ${ }^{1-3}$

Modern ideas on corneal transplantation had their origins not far from Oxford, at Litchfield in the Midlands. It was there that Erasmus Darwin, grandfather of Charles, a physician, scientist, philosopher, philanthropist, and a prolific writer of erotic poetry, ${ }^{+}$wrote the world's first textbook of systematic medicine, Zoonomia or the Law's of Organic Life." The book contained a sizeable section on keratitis, a particularly troublesome problem at that time, the era of Egyptian ophthalmia. It was in this section that Darwin wrote: 'Could not a small piece of cornea be excised with a trephine, the size of a small bristle or a large quill and would it not heal with a transparent scar?' These ideas were an uncanny prelude to the subsequent development of corneal transplantation as we know it today.

After Darwin there was a hundred years of experimentation before the first successful clinical grafts were achieved around the turn of the century. Some of this work was done in the laboratory, some in the clinic. One prominent contributor was Samuel Bigger of Dublin, who wrote the first scientific paper on corneal transplantation in 1837. ${ }^{6}$ He reported a large number of systematic experiments which he had carried out on rabbits. He described a number of phenomena affecting rabbit corneal grafts including allograft rejection: subsequent clouding of a graft after a period of intense inflammation. Of course he did not recognise the biological significance of what he was seeing; an understanding of the allograft response and the establishment of modern corneal transplantation biology did not occur for another hundred years. 
The science of transplantation biology also had its beginnings in Oxford with Sir Peter Medawar. In 1942 Medawar was a junior researcher in the Sir William Dunn School of Pathology, working under the supervision of Howard Florey. He was working on the toxicology of penicillin, healing of skin wounds, and seeking a role for lymphocytes. The function of lymphocytes was quite unknown at that time. His wife, Jean Medawar, described an incident in 1942 which had a profound effect on the development of transplantation biology and corneal transplantation. ${ }^{7}$ One sunny afternoon, when they were living in the Banbury Road, a bomber came in low over the house causing surprise and fear. Fortunately it was an allied bomber, but it crashed and burst into flames in the garden of a neighbour. The crew were badly burned. Their predicament apparently had an immediate and prolonged effect on Peter Medawar. From that point he directed all of his energies to the problem of skin transplantation, at first in a series of clinical studies carried out at Glasgow and subsequently in the laboratory at Oxford. His laboratory studies using rabbits were extensive and focussed, and provided the basis for his description of the uniqueness of the individual with respect to transplantation. These studies and subsequent studies carried out in Birmingham, after he stumbled across the phenomenon of tolerance in dizygotic twin calves, won him the Nobel Prize which he shared with Sir Macfarlane Burnet in 1960.

By the time Medawar had established the basic rules of allotransplantation, clinical corneal transplantation had been carried out with some success for 40 years. Clearly cornea was different from skin and this difference was attributed to the avascular nature of the cornea and described as immunological privilege. Recently it has been shown that the privilege is related to the relative acellularity of the cornea rather than its avascularity. ${ }^{8}$ The misconception that corneas do not reject has been passed down through generations of immunologists and has tended to be a barrier to attempts to engage adequate resources in research to overcome this difficult problem.

This is unfortunate because the majority of people in the world who require corneal grafts have scarred, vascularised and relatively cellular corneas and are very prone to rejection. The high graft failure rate is generally well appreciated by ophthalmologists and the research which has been carried out has influenced the way clinicians go about corneal transplantation on a day-to-day basis.

\section{CLINICAL DECISION MAKING IN CORNEAL TRANSPLANTATION}

Effective clinical practice is based upon making appropriate decisions. The essential raw material for effective decision making is relevant information. The information used by clinicians comes from various informal and formal sources. The clinician must be able to evaluate the information available and have some idea of the diverse approaches which are necessary to achieve an understanding of a complex problem such as corneal allograft survival. To a large extent the value of scientific information is determined by how it has been collected.
Information from Prospective Randomised Controlled Clinical Trials.

Although highly valued there are few data available from clinical trials concerning corneal transplantation, or any other branch of surgery. There is, however, some information available concerning the value of HLA matching for corneal transplantation. A recent multicentre study from the United States failed to demonstrate any advantage for attempts at better matching. ${ }^{9}$ This result contradicted previously published studies from various single centres. $^{10-14}$ There are several plausible explanations for the apparent contradiction.

One explanation is that the general care of the patients in a multicentre trial has achieved a better result for all patients than was achieved in a single centre study. A comparison of the results from one centre to another suggests that the control group in the multicentre trial did better than expected, better than they had done in the previously reported single centre studies. Perhaps in this case the topical immunosuppression used, an important consideration in the post-operative period, was optimal in the multicentre trial such that any difference attributable to matching was swamped. A similar phenomenon has been observed with matching for renal transplantation following the introduction of cyclosporin.

Another possible explanation is that the centre effect, the inexplicable differences from one centre to another, was such that these differences exceeded the reasonably small benefit anticipated from matching (Fig. 1).

There are a number of more general limitations to the usefulness of clinical trials for sorting out the effectiveness of therapeutic interventions such as corneal transplantation. Clinical trials have evolved in order to impose laboratory conditions on clinical studies. Clinical science is based on the life sciences. Biology grew out of, and alongside, the physical sciences, and chemistry and physics were considered 'real science' in advance of biology. These disciplines achieved their status because they had predictive value, and they had predictive value largely because of the power of classical mathematics to model linear systems. To a considerable extent, biologists have developed approaches to problems which provide quantifiable results in controlled situations. The inability of biologists to control all of the variables is reflected in the dependence of modern experimental biology on statistical evaluation and statements of probability. It is even more difficult to observe or measure, let alone control, all the variables in a clinical situation than it is in the biology laboratory. Not only are there so many variables, but they are constantly changing. Inadequate definition and transmutability are characteristic of clinical problems.

One aspect of the transmutability of clinical problems is the influence of downstream events on ultimate outcome. Clinical studies are necessarily long term, although never as long term as desirable, and post-randomisation events can have a profound effect on outcome and cannot be taken into account in conventional clinical trials in which patients are allocated to treatment groups on the basis of the initial clinical problem. 


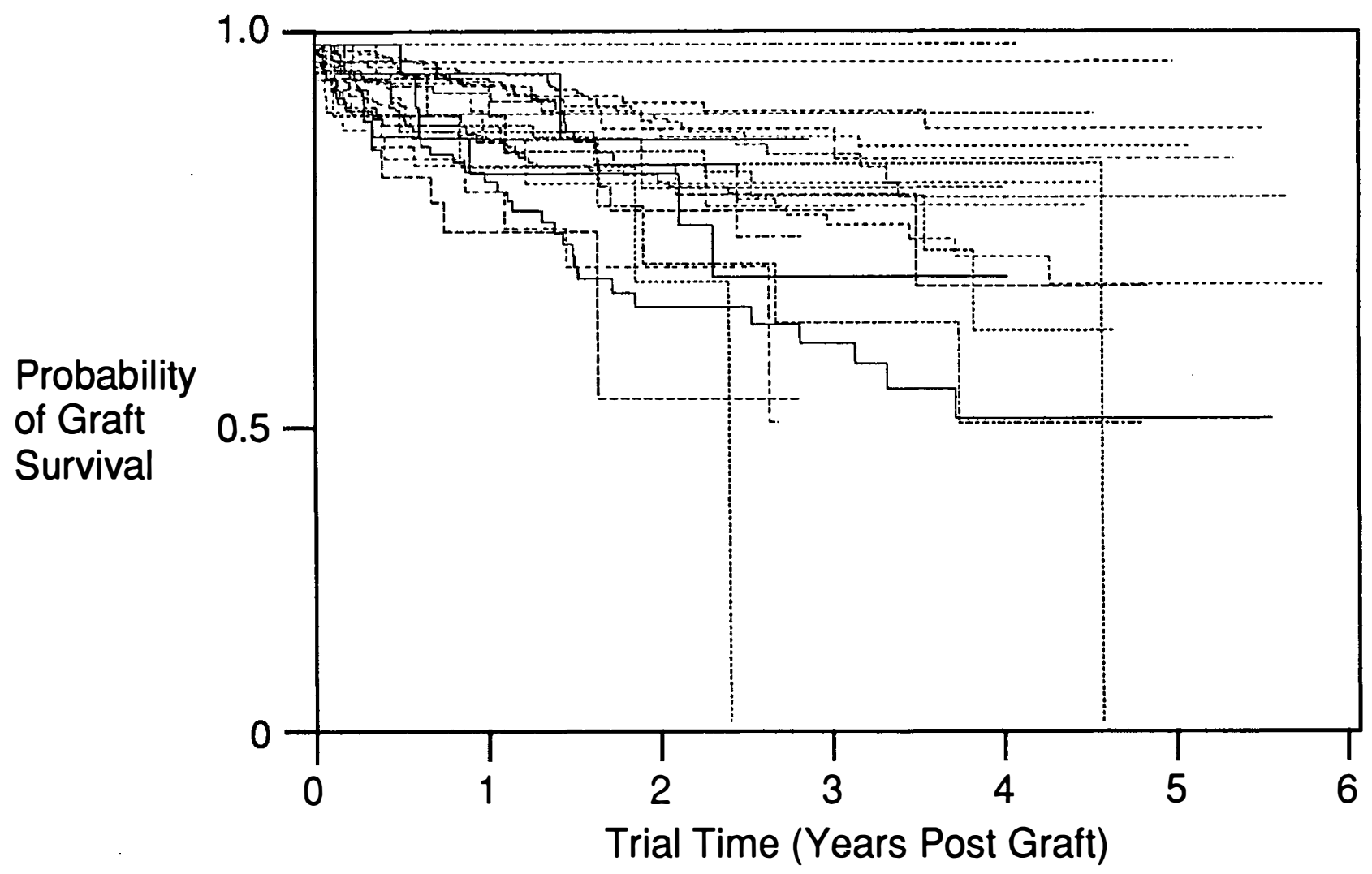

Fig. 1. The centre effect. There is a marked difference in graft survival between centres contributing to the Australian Corneal Graft Registry.

There is another conceptual problem. Clinical trials deliver results from a relatively well-defined clinical situation and are expressed in statistical terms. The clinician is faced with extrapolating this information to the circumstances of the patient sitting before him. Many philosophers and mathematicians claim that this conceptual leap cannot be made; that probability theory is based on a large series of events and cannot be extrapolated to the isolated case. What the clinician needs in order to narrow the gap for this leap of faith is more information.

The link between probability theory and advising the individual patient is common sense. The lack of certainty about the nature of a clinical problem, its mutability and the constant, apparently chaotic, interaction between patients and their illness and the real world is not confined to medicine. Such problems are everywhere. Not only in their professional lives but in their everyday activities, people are taking calculated risks. The leap between probability theory and an everyday decision is well-exercised common sense and adequate background information.

For example, if you were informed that the probability of rain in the afternoon was 0.9 you would realise immediately that this tells you nothing about the situation this afternoon. If, on the other hand, you knew that it was April, that it had rained this morning, the clouds were down to 200 metres, and you were in Glasgow, you would probably take your umbrella.

Clinical trials provide information about the probability of achieving a particular outcome with a particular treat- ment in a well-defined situation. Usually the information is generated as an answer to a narrow question studied in a brief time frame. In order to increase the breadth of circumstances studied in such trials it has been suggested that the results of all similar trials be added together prior to analysis (meta-analysis). Another way to achieve the breadth of observations relevant to real, chaotic clinical practice is through registries.

\section{Registry Data: The Australian Corneal Graft Registry}

Registries are another way of generating useful information. Registries are large systems of prospective data collection and progressive long-term follow-up. The extent of the data (large number of patients followed up through various individual incidences over many years) and the multiple sources of information, yield an apparently chaotic mass of data from which can emerge distinct and recognisable patterns of interaction. The management of the data and the recognition of patterns of interaction are facilitated by the ease with which modern information systems can store and analyse very large amounts of data.

The Australian Corneal Graft Registry demonstrates the value of a large, widely based register. Established in 1984 it grew out of the clinical records of patients having corneal grafts at Flinders Medical Centre. It now follows the course of 4500 patients, some of whom have been followed for 7 years. More than 300 surgeons from all over Australia have contributed information about their 
patients. Approximately $90 \%$ of the corneal grafts done in Australia are followed in the Registry. Reports are published every 2 years. 15.16

The large number of cases, the length of follow-up and the variations in clinical practice from one surgeon to another are related in the data collection. Critics of this type of approach are concerned about the variation in practice and reporting from one surgeon to another and from patient to patient. Rather than a weakness, this is a strength of the approach. The registry is an overview of a complex system of patients, clinical management and outcome. As such, it describes clinical practice as it really is. In this respect clinical registries are similar to the development of world-wide meteorological observation systems. These systems have evaluated the world's weather, recognising distinct but complex patterns. An understanding of these global patterns has resulted in greater predictability in weather forecasting at particular localities. Clinical registries have a similar role to play in sorting out the chaos of clinical interactions, and providing information relevant to forecasting the management requirements for individual patients.

\section{Analysis of Registry Data}

Even with modest beginnings registries very soon hold large amounts of data and analysis of the data can be attempted at several levels. At the simplest level, the effect of the initial conditions, the state of the recipient cornea at the time of surgery, the nature of the donor material used, and the type of surgery performed can be examined for an effect on outcome. This approach identifies a number of factors which are related to final outcome: the degree of vascularisation at the time of surgery, the amount of inflammation, the age of the donor, the storage conditions of the donor eye, etc.

However, it is not possible with this approach to determine whether these factors are true independent variables. This requires a more complicated approach employing multivariant analysis. This becomes possible when the number of observations becomes large. In the Australian Corneal Registry the Cox proportional hazards regression model is used. The essential manoeuvre in this approach is to pick out cases which are identical in all respects except one. Using this approach, the independent variables identified so far in the Australian Corneal Graft Registry are: inflammation at the time of surgery, the size of the graft, the number of grafts the patient has received, the diagnosis of keratoconus or a dystrophy as against an acquired corneal disease, aphakia, the presence of an anterior chamber or iris clip lens, the post-operative elevation of intraocular pressure, and wound dehiscence.

Downstream events, the involvement of pathology subsequent to surgery and various clinical incidents, can have a profound effect on outcome. The impact of these important events cannot be accommodated with conventional clinical trial design. Three such events which reach the level of being truly independent variables influencing graft outcome are wound dehiscence, a post-operative rise in intraocular pressure, and vascularisation to the wound margin.

Using this approach to identify independent variables requires a large number of patients to ensure that there are enough patients who vary in all respects but one. With insufficient numbers of patients independent variables may fail to emerge. For this reason it is important to scan the data examining outcome for as many different groups and variables as possible. This can be done with conventional survival statistics and the construction of KaplanMeier curves.

The Australian Corneal Graft Registry data provide some interesting information when analysed at this second level. One factor which has a statistically significant effect on outcome is the time at which sutures are removed: when sutures are removed within 6 months of surgery the prognosis is worse. The development of herpetic recurrence is also associated with a poor prognosis, as is the history of elevated intraocular pressure prior to surgery, even if the pressure has returned to normal prior to surgery.

It is important to cast a wide net. It is important to include in the assessment people other than clinicians so that clinical prejudice is overcome. Clinicians can hold strong but inappropriate views. For example, it is widely believed that younger donors provide better corneal donor material, but this cannot be demonstrated with the large number of observations made over a 7 year period (Fig. 2). However, it is possible that a difference will emerge with observations extended out to 20 or 30 years.

Another widely held misconception is that if a patient who has had an elevated intraocular pressure has the pressure returned to normal, either as a result of surgery or spontaneous regression prior to surgery, the prognosis is improved. The widely held view that an elevated intraocular pressure at the time of surgery is associated with a poor prognosis turns out to be true. It is also true that those who have a normal pressure at the time of surgery but who have had elevated intraocular pressure at some time in the past do not do any better than those patients who have elevated pressure at the time of surgery (Fig. 3). Similarly, the history of blood transfusion has an unexpected relationship with poor outcome. This is in contrast to the beneficial effect of blood transfusion on the outcome of renal transplantation. ${ }^{17}$

A broad overview of the patterns of disease, management and outcome provides the leads which need following up. The suggestions which come from the accumulating data and which are described above need careful evaluation in order to understand the phenomena observed and to determine their relevance to clinical practice. This may require further investigation in one way or another.

\section{WHAT IS AN APPROPRIATE OUTCOME?}

A limitation of all clinical evaluation is the relevance of the outcome measurement. It is conventional to assess the outcome of transplantation in terms of graft survival. This has its limitations in all forms of transplantation and 


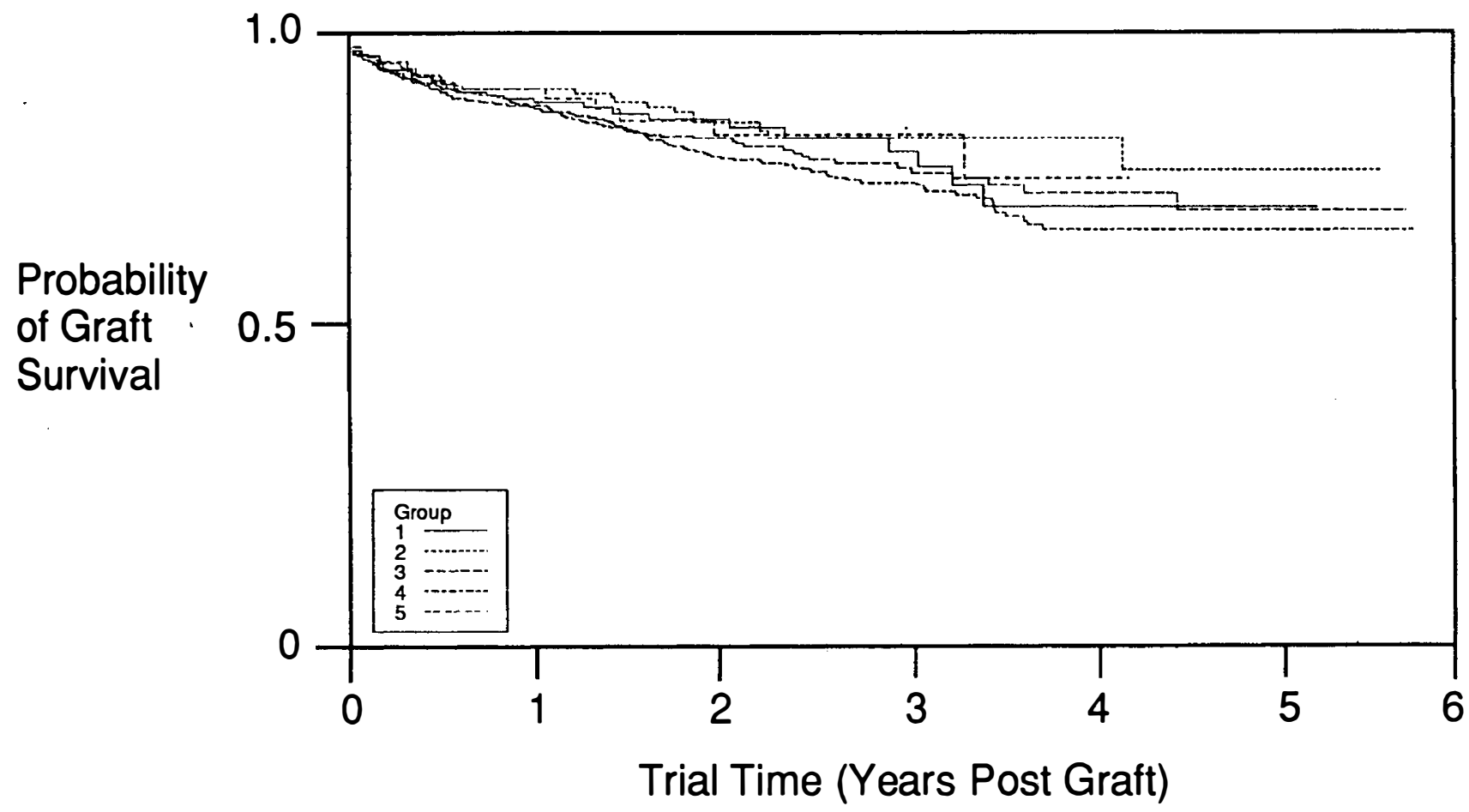

Fig. 2. The effect of donor age. The age of the donor does not influence graft survival. Group 1, <20 years; group 2, 21-40 years; group 3, 41-60 years; group 4, 61-80 years; group 5, >80 years.

patient survival and quality of life have come to be considered more important than graft survival. Long-term quality of life outcomes are important, particularly as the cost of organ transplantation rises. Such considerations are relevant to corneal transplantation as a large proportion of the patients receiving grafts are operated on for visual disability. For this reason the Australian Corneal Graft Registry has collected data on the visual perform-
Probability of Graft Survival

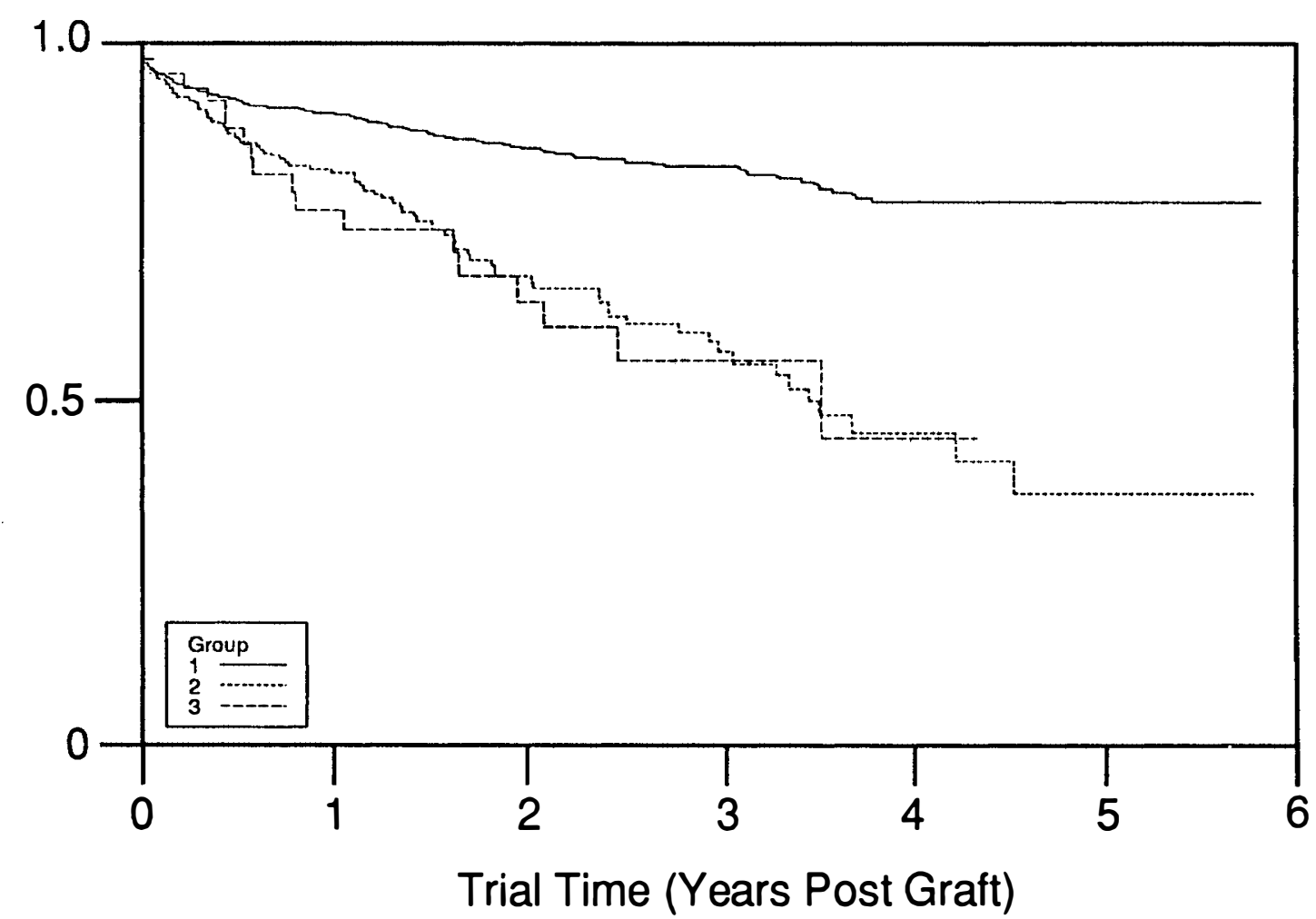

Fig. 3. The effect of elevated intraocular pressure. Patients with elevated intraocular pressure at the time of corneal transplantation do badly (group 2) compared with those who have never had a raised pressure (group 1). Those who have had raised intraocular pressure in the past but who have normal pressure at the time of surgery do no better (group 3). 
ance of eyes with corneal grafts. It is generally well appreciated that failed grafts result in poor vision, but not all eyes with clear grafts see well and, furthermore, not all patients who see well through their graft benefit in a functional sense. To clarify these issues it has been necessary to perform additional investigations.

\section{A Retrospective Study of Corneal Graft Outcome}

The Australian Corneal Graft Registry has broken new ground in attempting to assess the outcome of corneal transplantation in terms of visual results. Approximately $56 \%$ of patients achieved a vision of $6 / 18$ or better uncorrected in the operated eye. ${ }^{16}$ But since most corneal grafts are done for visual disability one is left wondering whether this approach goes far enough. Are conventional objective tests such as Snellen acuity an appropriate measure of functional outcome?

To answer this question a sub-group of consecutive patients were selected from the registry, brought back to the clinic and re-examined to establish the relationship between objective measures of visual outcome such as Snellen acuity, visual disability, and the patient's view of outcome. All the patients included in the study were operated on at the Flinders Medical Centre and had had their surgery at least 2 years previously, so that there was time for all refractive problems to have stabilised and to have received the appropriate management.

The assessment of outcome was done by someone outside the recognised treatment team. Patients had objective measurements of visual function and refraction recorded, they were given a questionnaire which examined their ability to function in their usual environment, and a series of questions which explored their attitude to the result they had achieved.

The results were striking and important. They showed that for a corneal graft to be successful the graft needed to be clear and functioning, the visual acuity needed to exceed the vision in the contralateral eye, and that this level of vision needed to be achieved without the requirement of a contact lens. ${ }^{18}$

These results underline the wisdom of Samuel Bigger of Dublin, who wrote in 1837 that it was important not to contemplate the procedure of corneal transplantation if there was tolerably good vision in the other eye. ${ }^{6}$ The most important lesson corneal surgeons learn with experience is how important it is to avoid operating on people with unilateral corneal disease. Visual disability is related to the performance of the better eye not the worse eye and, furthermore, patients with unilateral disease usually carry a full hand of risk factors for a poor prognosis. The results of this study therefore confirm the informal experience of surgeons and reiterate a message clearly set out in the first scientific paper published on corneal transplantation. ${ }^{6}$

\section{ANIMAL MODELS OF CLINICAL RELEVANCE}

Not all clinical research is carried out on patients. Laboratory studies have played an important role in defining and answering important questions concerning clinical corneal transplantation. Not all issues can be resolved by clinical studies. Some questions must be taken to the bench.

Animal models have been used extensively in corneal transplantation and have been used to address a wide range of questions. One of the most important questions has been the need to establish a better understanding of corneal allograft rejection. Allograft rejection is the most common cause of graft failure and a precise understanding of the underlying events opens up the possibility of more effective prevention and intervention.

A range of species has been used for experimental corneal transplantation. ${ }^{19}$ The most widely used animals are rabbits and rats. Rabbits have been used since the time of Bigger. In recent times an increasing proportion of in vivo experiments has been done in rats.

The rabbit is an appropriate animal to employ for corneal transplantation in that the eye is of a reasonable proportion facilitating predictable surgery, and the animals are relatively easy to handle and examine. Furthermore, rejection can be induced in a predictable manner, and although the normal endothelium has some capacity for replicative repair, corneal allograft rejection in the rabbit is essentially irreversible. The major disadvantage of using rabbits is that the immunogenetics are poorly defined; it is difficult to establish, maintain and characterise inbred strains; and the range of immunoreagents is limited.

In order to overcome these serious disadvantages a model of corneal transplantation employing inbred strains of rats was developed in our laboratory. ${ }^{20}$ It has since been widely employed to study corneal allograft rejection. However, the model does have serious limitations. The replicative capacity of the rat corneal endothelium is considerable so that the rejection may be a transient event with endothelial replacement accounting for rejected corneas regaining clarity. ${ }^{21}$ This can make endpoint definition uncertain. Another disadvantage is that the animals are so small that systemic absorption of drugs delivered in eye drops can become a significant consideration. The rat model is best used when immunogenetics are of prime concern and the model has been very well used for this purpose. ${ }^{22-24}$

No one animal model is satisfactory for all purposes. A range of animal models must be used in order to address a range of questions. The information gained from the rabbit and rat models is complementary. In general terms the rabbit model has been used to define the morphological and cellular aspects of corneal allograft rejection and the rat model has been used to look more closely at immunological events and to explore the immunogenetics of allograft rejection. These studies have demonstrated that in addition to class I and class II antigens, the minor histocompatibility antigens are important in rejection. ${ }^{24}$ They have also demonstrated the importance of bone marrow derived cells in the corneal bed at the time of transplantation in generating graft rejection. ${ }^{8}$ These host cells 
present foreign antigen to host immunocytes. This has been confirmed in vitro. ${ }^{25}$ The importance of indirect antigen presentation is therefore relatively more important in corneal transplantation than it might be in other forms of organ allograft rejection. Although the afferent arm of the corneal allograft response is highly specific, the efferent arm involves large numbers of polymorphs and macrophages, suggesting that at least some of the damage is not specifically, mediated (Fig. 4). ${ }^{26}$

In recent times, attention has turned from defining the cellular events of rejection to developing a better understanding of the molecular signalling between cells which orchestrates the complex elements of the rejection process. Increasingly, the techniques of molecular biology are being applied to this puzzle. A better understanding of the molecules on the surface of cells and the soluble cytokines involved in allograft rejection may show the way to more specific therapeutic interventions.
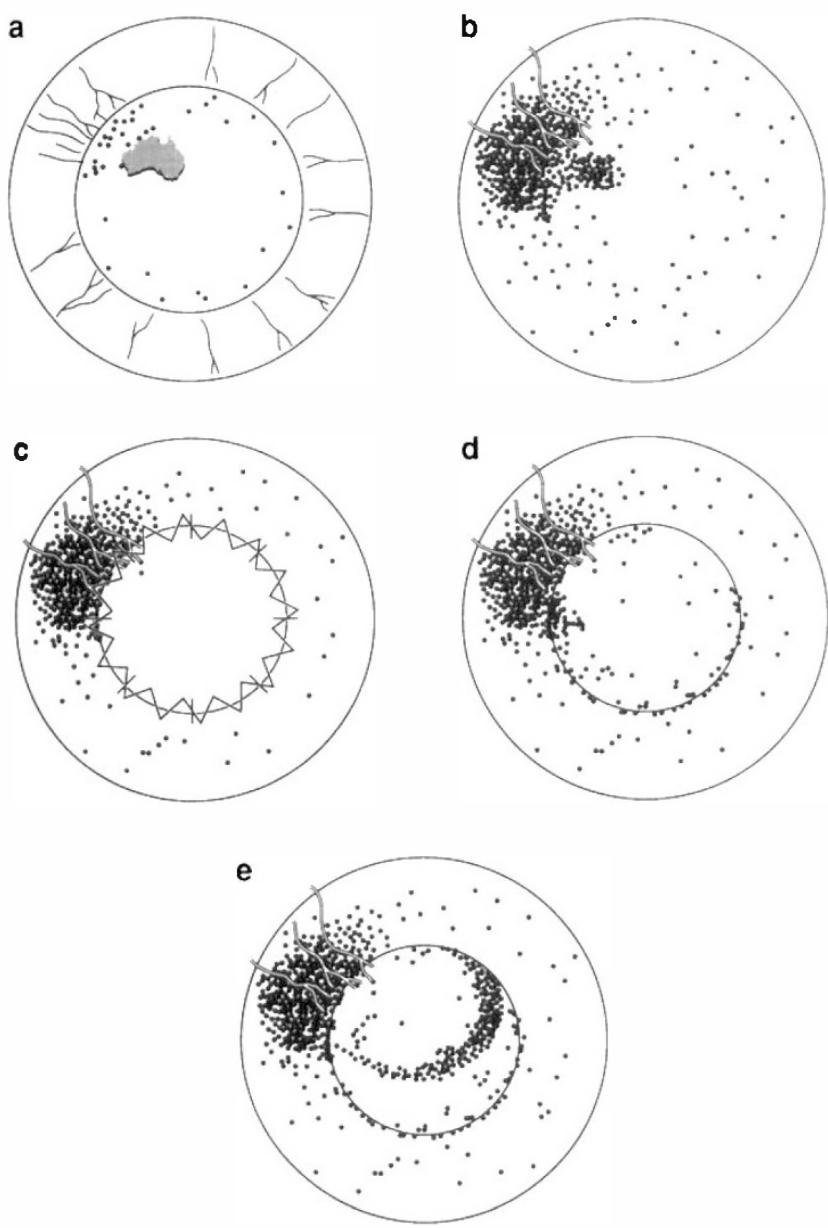

Fig. 4. Cellular processes in corneal allograft rejection. With inflammation bone-marrow-derived cells accumulate in the cornea and, with time, vascularisation may occur $(a)$. The inflammatory cells persist in the cornea for years - perhaps indefinitely $(b)$. At the time of surgery the infiltrated cornea is excised and replaced with a donor cornea relatively free of inflammatory cells (c). Host cells populate the cornea via the wound margin with wound healing, or should the graft become inflamed $(d)$. These host cells present graft antigens to the host immune system (indirect antigen presentation). The efferent phase, easily seen clinically, involves the recruitment of a large number of inflammatory cells $(e)$.
In order to apply powerful new techniques used in identifying molecular events, new animal models are required. To this end, a sheep model of corneal transplantation has been developed in order to exploit the wide range of molecular probes available for this species.

\section{CLINICAL ANECDOTES: LIMBAL STEM CELL ALLOTRANSPLANTATION}

Not all clinical problems are amenable to observation in clinical trials or registries. These approaches are useful for studying the impact of interventions which have reached a reasonably sophisticated level of development. New procedures need to be developed before they can be assessed. Furthermore, because relatively large numbers of observations must be made to generate meaningful data, trials and registries cannot be applied to the study of rare conditions or unusual treatments.

The management of ocular surface disorders with limbal allografts is an example of a new treatment for a relatively uncommon condition. The early stages demand close observation of the small number of cases where the individual circumstances have justified the use of a relatively untried procedure.

Ocular surface disorders are usually very damaging to vision and significant ocular surface pathology is generally considered to be an absolute contraindication to corneal transplantation. Maintenance of the corneal surface is mandatory for graft survival. Usually ocular surface disorders involve the cornea, conjunctiva and lids. Sometimes the disease is confined to the cornea. In such cases corneal epithelial opacity, keratinisation of the epithelium, oedema of the epithelium and underlying stroma, and corneal vascularisation are prominent features. Conjunctivalisation of the epithelial surface can occur with a disturbance of the epithelial cell-tearfilm complex and associated dysplastic changes in the epithelium. This pathology is attributed to failure of limbal epithelial stem cells to generate appropriately differentiated corneal epithelium.

In recent years, the transplantation of limbal stem cells has been advocated for this group of disorders. ${ }^{27-29}$ Various forms of a similar technique involving excision of the diseases limbus and transplantation of peripheral cornea and conjunctiva containing the limbal epithelium have been developed. This approach is usually advocated for unilateral disease where there is a donor site available from the contralateral eye. However, in the most severe cases both eyes are affected similarly. In these situations it is appropriate to consider allografts. ${ }^{30}$

\section{Case 1. Contact-Lens-Induced Dysplasia Treated with} Limbal Stem Cell Allografts

A 30-year-old woman first presented in 1983, having worn contact lenses for 3 years. For 6 months prior to presentation she had discomfort and poor vision. The visual acuity was $6 / 12$ in each eye, but there were obvious linear opacities in the cornea with opacification of the peripheral corneal epithelium and vascularisation of the limbus. The 
conjunctiva was normal. A corneal biopsy was performed and it revealed a dysplastic process. Over several years the opacity increased and came to involve all of the cornea of both eyes. In $1992 \mathrm{her}$ vision had reduced to 6/60 right and left, the entire cornea being affected by the process with vascularisation, oedema and epithelial keratinisation. A diagnosis of contact-lens-induced corneal dysplasia was made. By this stage the patient was disabled by her poor vision. It was considered appropriate to manage her with a limbal stem cell allograft under systemic immunosuppression. Two arcs of limbus of approximately $90^{\circ}$ were excised and replaced with allografts. After the surgery she made a remarkable recovery and achieved $6 / 12$ vision with resolution of the pre-operative epithelial signs. This level of improvement has been maintained over 12 months. There has been no sign of allograft rejection, but immunosuppression with cyclosporin and azathioprine has been maintained.

Case 2. Limbal Neoplasia Treated with Excision and Limbal Stem Cell Allotransplantation

A. 63-year-old man presented with an extensive neoplasm which had been treated with excision. The disease reestablished itself and further re-excision and cryoablation was performed. This controlled the disease but his vision was reduced to $6 / 60$ because of epithelial pathology, including keratinisation, vascularisation and superficial stromal oedema. The corneal changes were attributed to a defective limbus as a consequence of the original pathology and its subsequent treatment with surgery and cryotherapy. He agreed to limbal transplantation but was not prepared to have a graft from the normal contralateral eye, or to have immunosuppression. Two arcs of limbus of approximately $90^{\circ}$ were excised and replaced with limbal allografts. Within a few days of surgery the abnormal corneal epithelium was replaced with apparently normal corneal cells. His vision improved to $6 / 12$, he became more comfortable and the pre-operative inflammation disappeared. This improvement was maintained for 6 months but the disease in the non-grafted areas reappeared and tended to overwhelm the normal areas in the vicinity of the grafts. At no stage was there any sign of rejection(Fig. 5).

\section{Case 3. Severe Chemical Burns Treated with Limbal Stem Cell Allografts}

A 35-year-old man was blinded following an assault with concentrated acid. He suffered severe damage to his head and neck in general and his eyes in particular. After reconstructive surgery, to overcome severe facial and eyelid scarring, a right corneal graft was performed. The prognosis was understood to be poor. The regaining of navigational vision was the aim of intervention. Because of the poor prognosis systemic immunosuppression with cyclosporin and azathioprine was used. Not surprisingly, the graft developed ocular surface problems with recurrent ulceration and scarring which eroded an acceptable early result. Allograft rejection did not occur despite extensive superficial vascularisation of the graft. Six months after the initial graft the scarred and vascularised host limbus and peripheral cornea was excised up to the junction of the penetrating central corneal graft. This was replaced with a corresponding annulus of donor tissue and a $10 \mathrm{~mm}$ fringe of conjunctiva. Following this, the corneal surface was well maintained for another 6 months and in the initial period he achieved and maintained navigational vision. However, after this period his vision decreased due to progressive optic nerve dysfunction which occurred despite normal intraocular pressure. The ocular surface also deteriorated, developing widespread staining with Bengal Rose, but after a year he had not developed ulceration or vascularisation.

These results do not justify the immediate adoption of limbal allografts for the treatment of corneal surface disorders. They are no more than anecdotes with encouraging short-term outcomes. However, they do suggest some questions which need to be taken to the laboratory bench in search of answers.

The clinical course of the three patients described above was unusual, or at least unexpected. Although the immediate effect of the procedure was striking in all three cases, the effect was not completely maintained in the long term in two of them. However, there was no obvious allograft rejection observed, even in the case in which no immunosuppression was used. This was surprising in view of the anticipated allogenicity of peripheral cornea and conjunctiva.

This is not the most surprising aspect of these cases. An attempt was made to identify whether the cells on the ocular surface after limbal allotransplantation were of donor or host origin. PCR technology was used to look for non-recipient micro-satellite DNA repeats. No evidence of donor cells could be found. Whilst this identification cannot be conclusive it does raise the possibility that the graft has improved host corneal epithelial cell growth and differentiation. There is a need for a better understanding of relevant biology. This requires the development of animal models and experiments to identify the means by which corneal epithelial cell growth and differentiation is controlled. Progress is being made on both fronts.

The communication between epithelial cells and the supporting stroma is complex. A number of different cytokines are involved. They are produced by both epithelial and stromal cells, and it appears that some cytokines produced by peripheral corneal keratocytes have receptors on peripheral corneal epithelial cells. ${ }^{31}$ Perhaps the healing response of the graft is to supply normal cells, which are producing a repertoire of cytokines for a short time, that in some way improve epithelial growth and differentiation of the host (Fig. 6). There is much work to be done before the full potential of this approach can be realised.

\section{CONCLUSION}

Working in the field of corneal transplantation and watching the development of related science over the last 20 years leaves me with mixed feelings about the progress which has been made. On the one hand, there is little doubt 


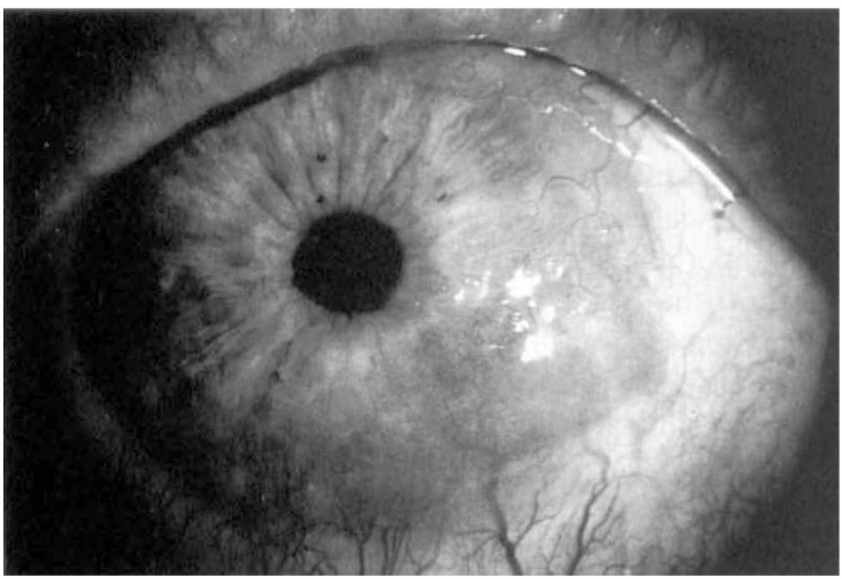

(a)

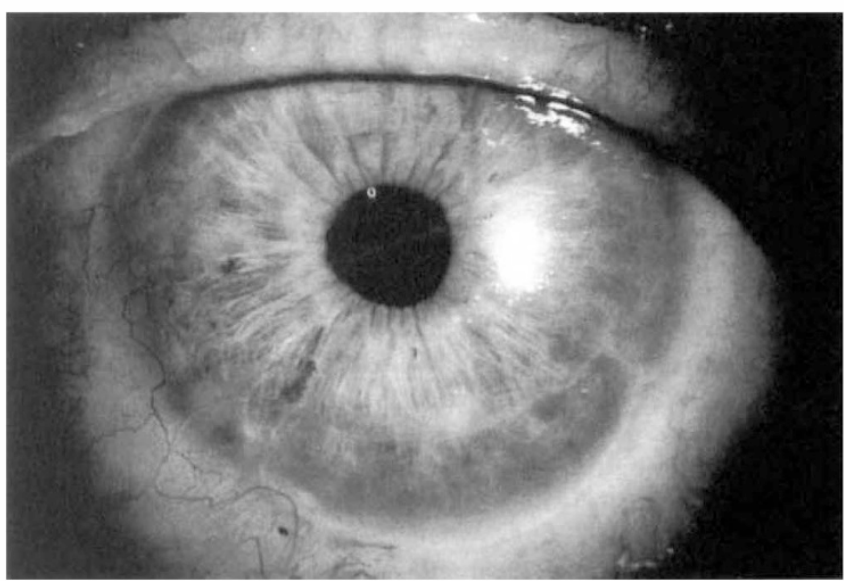

(b)

Fig. 5. Case 2. Widespread limbal disease and central epithelial dysplasia in a 65-vear-old man with extensive, recurrent, limbal neoplasia $(a)$. Six months after limbal allografts the central epithelial signs had reverted to normal (b).

that the information which has been accumulated about the procedure has improved clinical practice. In my own case, there has been a measurable improvement in graft survival over three successive 3 year periods (Fig. 7). This improvement can only be attributed to better decision making.

Although corneal transplantation appears to be a highly successful procedure the published results do not give an

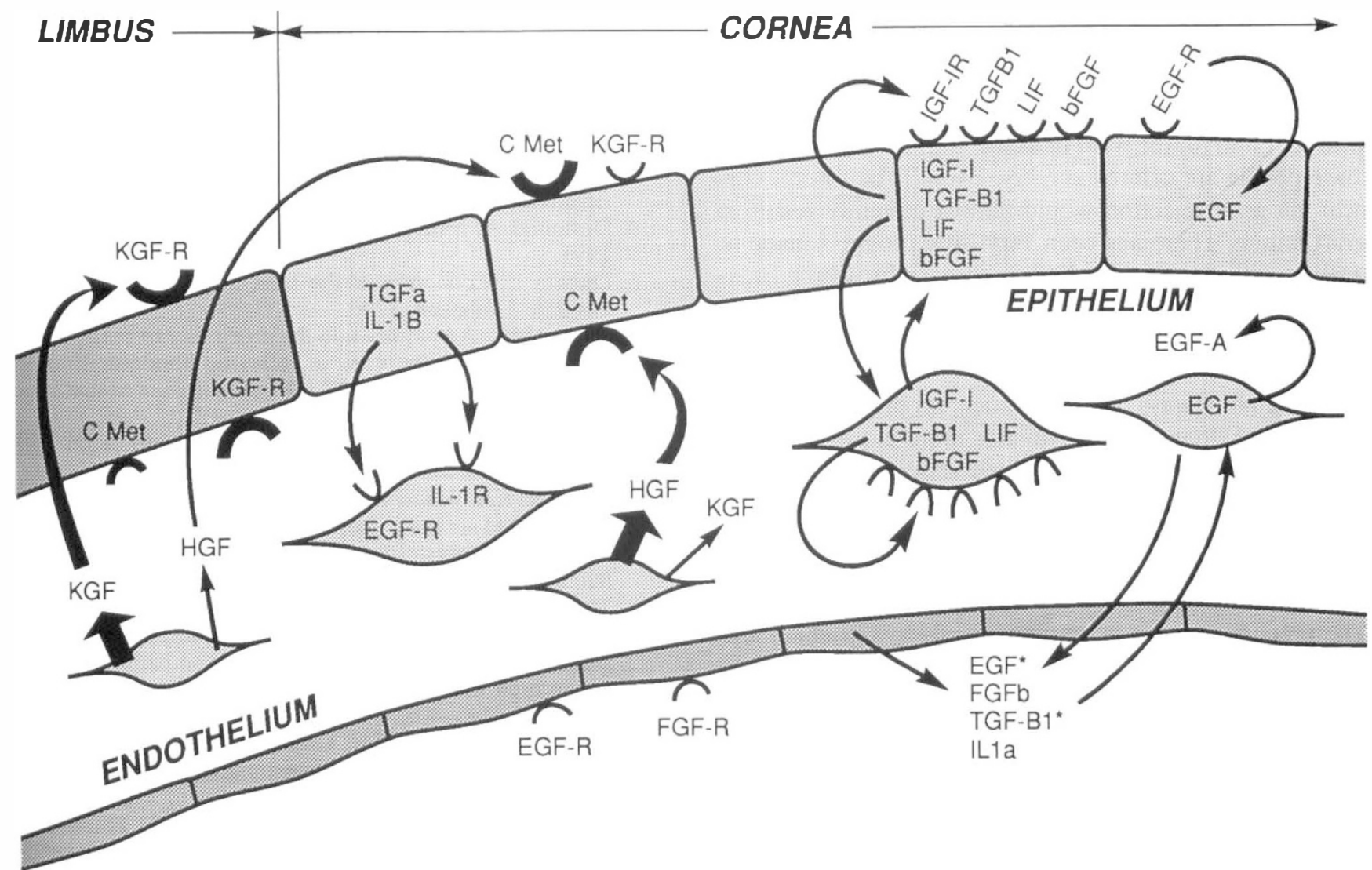

Fig. 6. Elements of the cytokine netw'ork of the cornea. Cells in all lavers produce cytokines. Receptors for a particular cell mav be on the producing cell or on a different cell. There are regional differences in cytokine production and receptor expression. For example, in the limbal area the keratinocytes produce more keratinocyte grow th factor than hepatocyte growth factor and the limbal epithelium in the same region expresses more keratinocyte grow th factor receptor than hepatocyte grow th factor receptor. The reverse is the case for the central cornea. This map is based on PCR technology and assumes, therefore, that there is no post-transcriptional control. KGF, keratinocyte growth factor; HGF, hepatocyte growth factor; LIF, leukaemia inhibitory factor; IGF-I, insulin-like growth factor I, $T G F-B 1$, transforming growth factor $B ; b F G F$, basic fibroblast grow'th factor; EGF, epidermal growth factor; IL-1a, interleukin-1a; $I L-1 B$, interleukin- $I B$; TGFa, transforming grow'th factor $a$. The suffix ' $R$ ' or '- $R$ ' indicates the receptor for that grow'th factor; the exception is C Met, which is the receptor for HGF. (Adapted from Li and Tseng." and Wilson and Lloyd ${ }^{32}$ ). 


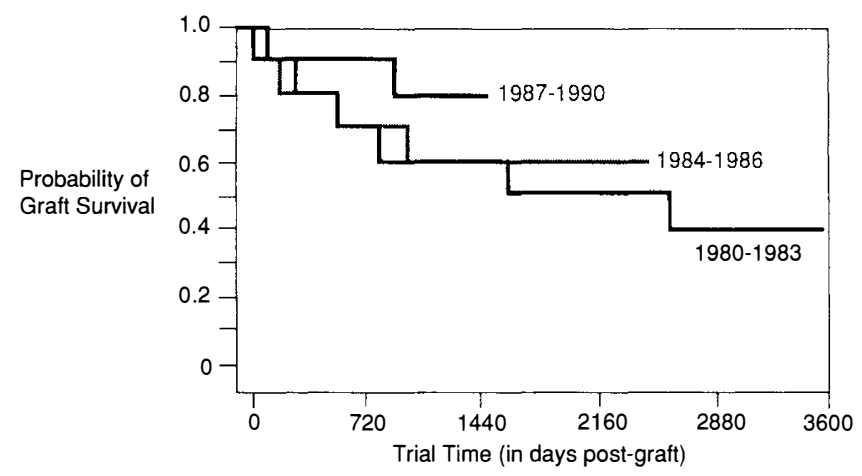

Fig. 7. Graft survival for a consecutive series of patients done by one surgeon (D.J.C.) over three successive 3 year periods. The progressive improvement is attributable to improved decision making.

accurate picture of the level of development. As with all other procedures this must be judged against the full potential of the procedure rather than the achievements to date. This demands an international perspective. Most of the corneal transplantation carried out in the world is done in developed Western countries where keratoconus and corneal dystrophies are relatively common indications. However, corneal disease has more impact in developing countries where acquired corneal diseases account for a high proportion of the blindness. There are many thousands, even millions, of people in developing countries who are blind for the want of a clear cornea. Hardly any of these people are offered surgery. Even if they were, corneal allograft rejection would almost certainly result in graft failure. There has been very little progress made in dealing with the type of blinding disease for which Erasmus Darwin originally proposed the procedure. On the other hand, gradual progress is a necessary preparation for revolution.

'Mankind always takes up such problems as it can solve: since, looking at the matter more closely we will always find that the problem itself arises only when the material conditions necessary for its solution already exist or are at least in the process of formation.' This quotation comes from Karl Marx and refers to social revolution. But the statement applies equally well to science, and to art. The preparations for revolution are always gradual, and we tend to consider questions for which there are likely to be answers.

The matters which I have discussed here provide information for contemporary clinicians to use on a day-to-day basis. They also provide the preparation for revolution. Science, particularly in the fields of immunology and molecular biology, is providing very powerful tools so that more penetrating questions can be addressed and it is likely that before too long things will be done quite differently. Perhaps there will be artificial corneas; many groups are working in this area. Perhaps it will be the use of gene therapy to mask the immunological markers on corneal donor cells, so that the host cannot recognise what is foreign. Perhaps the leap will be made in some way that we cannot, at this point, even imagine. When the revolu- tion comes, all of our established information will suddenly lose its currency - these will be better days.

\section{SUMMARY}

The current status of corneal transplantation is determined by historical events and current research findings. Many of the important historical events occurred in and around Oxford: the beginning of visual science, corneal transplantation and transplantation in immunology. Contemporary research yields data from a number of different sources: clinical trials, registries, surveys, animal experiments and in vitro studies. This information has been used by clinicians to bring about a steady improvement in the outcome of corneal transplantation.

Keryn Williams, PhD, my long-standing colleague, has generated the data reported from our Flinders Medical Centre laboratory. She has also been responsible for my continued interest in this subject and the development of many young surgeon scientists working in the field of corneal transplantation. Figures 1,2 and 3 are reproduced with permission of the Australian Journal of Ophthalmology.

Key words: Clinical trials, Corneal transplantation, History, Laboratory science.

\section{REFERENCES}

1. McEvoy J. The philosophy of Robert Grosseteste. London: Oxford University Press, 1982.

2. Combie AC. Robert Grosseteste and the origins of experimental science. London: Oxford University Press, 1953

3. Prest J (ed.). The illustrated history of Oxford University. London: Oxford University Press, 1993.

4. Desmond A, Moore J. Darwin. London: Michael Joseph, 1991.

5. Darwin E. Zoonomia or the laws of organic life. Vol II. London: J Johnson, 1796.

6. Bigger SLL. An inquiry into the possibility of transplanting the cornea, with the view of relieving blindness (hitherto deemed incurable) caused by several diseases of that structure. Dublin J Med Sci 1837;11:408-17.

7. Medawar J. A very definite preference: life with Peter Medawar. London: Oxford University Press, 1991.

8. Williams KA, White MA, Ash JK, Coster DJ. Leukocytes in the graft bed are associated with corneal graft failure: analysis by immunohistology and actuarial graft survival. Ophthalmology 1989;96:38-44.

9. The Collaborative Corneal Transplantation Studies Research Group. The collaborative corneal transplantation studies (CCTS): effectiveness of histocompatibility matching in high-risk corneal transplantation. Arch Ophthalmol 1992;110:1392-403.

10. Batchelor JR, Casey TA, Gibbs DC, Lloyd DF, Werb A, Prasad SS, James A. HLA matching and corneal grafting. Lancet 1976;1:551-4.

11. Sanfilippo F, MacQueen JM, Vaughn WK, Foulks GN. Reduced graft rejection with good HLA-A and -B matching in high risk corneal transplantation. N Engl J Med 1986;315: 29-35.

12. Volker-Dieben J, D'Amaro J, Kok-Van Alphen CC. Hierarchy of prognostic factors for corneal allograft survival. Aust NZ J Ophthalmol 1987;15:11-8.

13. Boisjoly HM, Roy R, Dube I, Laughrea PA, Michaud R, Douville P, Hebert J. HLA-A, B and DR matching in corneal transplantation. Ophthalmology 1986;93:1290-7.

14. Beekhuis WH, van Rij G, Renardel de Lavalette JGC, Rinkel-van Driel E, Persign G, D'Amaro J. Corneal graft 
survival in HLA-A and HLA-B-matched transplantations in high-risk cases with retrospective review of HLA-DR compatibility. Cornea 1991;10:9-12.

15. Williams KA, Roder D, Esterman A, Muehlberg SM. Coster DJ. Factors predictive of corneal graft survival: report from the Australian Corneal Graft Registry. Ophthalmology 1992;99:403-14.

16. Williams KA, Muehlberg SM, Wing SJ, Coster DJ on behalf of all contributors. The Australian Corneal Graft Registry. Aust NZ J Ophthalmol 1993;21:3-48.

17. Opelz G, Graver B, Terasaki PI. Induction of high kidney graft survival rate by multiple transfusion. Lancet 1981:1: $1223-5$.

18. Williams KA, Ash JK, Pararajasegaram P, Harris S, Coster DJ. Long-term outcome after corneal transplantation: visual result and patient perception of success. Ophthalmology 1991;98:651-7.

19. Williams KA, Coster DJ. Clinical and experimental aspects of corneal transplantation. Transplant Rev 1993;7:44-64.

20. Williams KA. Coster DJ. Penetrating corneal transplantation in the inbred rat: a new model. Invest Ophthalmol Vis Sci 1985;26:23-30.

21. Tuft SJ, Williams KA, Coster DJ. Endothelial repair in the rat cornea. Invest Ophthalmol Vis Sci 1986;27:1 199-204.

22. Callanan D, Peeler J, Niederkorn JY. Characteristics of rejection of orthotopic corneal allografts in the rat. Transplantation 1988;45:437-43.

23. Katami M, Madden PW, White DJ, Watson PG, Kamada N.
The extent of immunological privilege of orthotopic corneal grafts in the inbred rat. Transplantation 1989;48:371-6.

24. Katami M. Corneal transplantation: immunologically privileged status. Eye 1991:5:528-48.

25. Williams KA, Ash JK, Mann TS, Noonan FP, Coster DJ. Cells infiltrating inflamed and vascularized corneas. Transplant Proc 1987:19:2889-91.

26. Williams KA, Standfield SD, Wing SJ, Barras CW, Mills RA, Comacchio RM, Coster DJ. Patterns of corneal graft rejection in the rabbit and reversal of rejection with monoclonal antibodies. Transplantation 1992;54:38-43.

27. Thoft RA. Keratoepithelioplasty. Am J Ophthalmol 1984; 97:1-6.

28. Roat MI, Thoft RA. Ocular surface epithelial transplantation. Int Ophthalmol Clin 1988;28:169-74.

29. Turgeon PW, Nauheim RC, Stopak SS, Roat MI, Thoft RA. Indications for keratoepithelioplasty. Arch Ophthalmol 1990; 108:233-6.

30. Thoft RA, Sugar JS. Graft failure in keratoepithelioplasty. Cornea 1993;12:362-5.

31. Li DQ, Tseng SCG. Cytokine network between human limbal or corneal epithelium and fibroblasts [abstract]. Invest Ophthalmol Vis Sci 1993:34:1011.

32. Wilson SE, Lloyd SA. Epidermal growth factor, transforming growth factor beta-1, and interleukin- $1 \alpha$ messenger RNA production in human corneal endothelial cells. Invest Ophthalmol Vis Sci 1991:32:2747-56. 